\title{
O ENSINO DE PSICOLOGIA E A EDUCAÇÃO INFANTIL: A NOVA POLÍTICA PÚBLICA PARA A EDUCAÇÃO INFANTIL E O ENSINO FUNDAMENTAL E SUAS POSSÍVEIS REPERCUSSÕES PARA O DESENVOLVIMENTO PSICOLÓGICO INFANTIL
}

\section{Maria Silvia Pinto de Moura Librandi da Rocha}

\section{RESUMO}

O objetivo deste texto é abordar questões que permitam refletir sobre desafios enfrentados pelo ensino de Psicologia quando este focaliza a Educação Infantil. Optou-se por tematizar estas reflexões a partir da mudança recentemente implantada no sistema educacional brasileiro, tornando obrigatório que as crianças saiam mais cedo das pré-escolas e tenham antecipado o seu ingresso no Ensino Fundamental, para os 6 anos de idade. Os possíveis impactos desta mudança são analisados focalizando a atividade lúdica, com especial ênfase nas brincadeiras de faz-de-conta. Para estas análises, toma-se como pontos de sustentação conceitos da teoria histórico-cultural (especialmente os trabalhos de Vygotsky, L.S., Leontiev, A. N. e Elkonin, D. B.), os documentos oficiais propostos como referências para o trabalho com crianças (publicados pelo MEC) e o que tem sido possível identificar nas práticas educacionais em relação às brincadeiras infantis. O texto problematiza as relações entre estes discursos (permeadas por contradições) e sugere que o enfrentamento destas pode se constituir em compromisso extremamente importante nas atividades de docência que abordam as inter-relações entre Psicologia e a educação de crianças pequenas.

\section{PALAVRAS-CHAVE}

Desenvolvimento infantil; Atividade lúdica; Práticas educativas

\section{THE TEACHING OF PSYCHOLOGY AND PRESCHOOL: THE NEW PUBLIC POLICIES FOR PRE AND ELEMENTARY SCHOOL AND ITS POSSIBLE REPERCUSSIONS FOR CHILD PSYCHOLOGICAL DEVELOPMENT}

\begin{abstract}
The objective of this text is to deal with issues which allow us to reflect upon the challenges faced in the teaching of psychology towards preschool. These reflections were highlighted after the recent changes made in the Brazilian educational system, which determines that kids leave preschool one year earlier, and start elementary school at the age of 6. The possible impacts of this change are analyzed having in focus the playful activity, with special stress on the make-believe activities.In order to make these analyses, concepts of the historical-cultural theory are taken as background, especially the works of Vygotsky, L.S., Leontiev, A.N. And Elkonin, D. B.), the official documents proposed as reference for working with kids (issued by MEC) and what have been possible to identify in the educational practices regarding child's play. The text brings the questions between these two discourses (surrounded by contradictions) and suggests that the understanding of them may create an extremely important commitment in the teaching activities which approach the interrelations between Psychology and the education of young learners.
\end{abstract}

\section{KEYWORDS}

Kids development; Playful activities; Educational practices

(C) ETD - Educação Temática Digital, Campinas, v.8, n.2, p.266-277, jun. 2007 - ISSN:1676-2592 266 
A atividade lúdica corre riscos de se tornar prática de uma infância do passado?

O ensino de Psicologia vai poder pular as páginas e capítulos que foram dedicadas por esta ciência a esta esfera de atividade humana?

As páginas e capítulos que abordam os jogos de faz-de-conta correm especial risco de se tornarem meras peças de curiosidade histórica?

Ao ser convidada a produzir um texto para provocar o aquecimento de discussões tendo como referência o Ensino de Psicologia e a Educação Infantil, entendi que seria um momento e um fórum bastante promissor para discutir o que considero (e, suponho, não estar de modo algum sozinha) o fato mais importante recentemente imposto a este segmento educacional: a implantação do Ensino Fundamental de 9 anos.

O ano de 2006 representa, seguramente, um marco na história das políticas públicas em relação à infância das crianças brasileiras, às suas experiências educacionais e às possíveis contribuições destas para o desenvolvimento psicológico infantil. Trata-se da data em que se decidiu implantar a ampliação do Ensino Fundamental para 9 anos. Prevista na LDB de 1996 (lei n 9.394/96) e em uma das metas do Ensino Fundamental no Plano Nacional de Educação (PNE, aprovado pela Lei 10.172/2001), tem sua definição legal a partir de 6 de maio de 2006, com a promulgação da Lei $n^{0}$ 11.274, que altera a LDB e expande a faixa de frequiência escolar obrigatória, incluindo, a partir de então, crianças de 6 anos.

Existem, claro, várias formas de abordar e analisar este fato. A escolhida aqui é refletir sobre os impactos que podem advir dele, especialmente no que se refere a uma atividade de extrema importância para o desenvolvimento psicológico das crianças: a atividade lúdica. Proponho que (ao menos para início das reflexões) as considerações sobre esta atividade sejam feitas à luz da teoria histórico-cultural, especialmente em função de duas razões: (i) por considerar uma matriz teórica da Psicologia que traz excepcionais contribuições para se refletir sobre as relações entre práticas educacionais e desenvolvimento psicológico e (ii) por vir sendo (esta matriz teórica) indicada como uma das principais referências da Psicologia para as reflexões sobre a infância e propostas educacionais nos documentos oficiais - produzidos para servirem de referências e guias 
sobre como se deve organizar tanto a Educação Infantil quanto o Ensino Fundamental (BRASIL, 1998, 1998a, 1998 b e 2006).

A seguir, serão feitas algumas considerações sobre o tema, colocando em evidência alguns dos fundamentos teóricos da Psicologia vygotskiana, os modos como são apropriados pelos documentos oficiais e os efeitos disso nas práticas educacionais concretas.

\section{A ATIVIDADE LÚDICA NOS DOCUMENTOS OFICIAIS E NA TEORIA HISTÓRICO-CULTURAL}

Os três volumes do Referencial Nacional para a Educação Infantil (RCNEI) têm sido objeto de críticas contundentes quanto ao modo como se aborda a atividade lúdica nestes documentos (por exemplo em FARIA, PALHARES,. et al., 1999¹; ARCE, 2006). Embora haja reconhecimento sobre a importância de constar nos textos referências claras sobre a relevância da atividade lúdica no desenvolvimento infantil e nos contextos educacionais, pelo menos dois tipos de problemas vêm sendo apontados: (i) o que se considera como lugar ainda tímido destinado à brincadeira, não assumida plenamente como a prática mais importante da Educação Infantil, permanecendo o perigo de ser usada como instrumental para a aprendizagem de conceitos culturalmente mais valorizados ${ }^{2}$; (ii) a tendência de naturalização da concepção de brincadeira trazida pelo RCNEI, antagônico ao que propõem os autores da Psicologia Histórico-cultural, assumidos como fonte de referência fundamental na construção dos documentos.

É possível estender estas críticas ao mais novo documento oficial sobre Ensino Fundamental de 9 Anos (BRASIL, 2006). Ainda que seja louvável - assim como no RCNEI - a preocupação em apresentar a atividade lúdica como um direito a ser garantido às crianças (e o documento dá pistas de que deseja-se que isto ocorra não somente com

\footnotetext{
${ }^{1}$ As críticas ao RCNEI neste livro referem-se não apenas ao tema do brincar, sendo tecidas considerações também sobre vários aspectos desta produção, tais como problemas na estruturação do material e da linguagem utilizada, nas concepções de crianças, educadores e escolas que apresenta, predomínio de referências advindas da Psicologia e a ausência ou pouco aproveitamento de contribuições de outras áreas do conhecimento humano, tais como a Sociologia, a Lingüística, entre outros.

${ }^{2}$ Com relação a este modo de utilização das brincadeiras das crianças voltaremos a fazer algumas considerações mais à frente.
} 
relação às de 6 anos, mas também às mais velhas que compartilham com estas o mesmo espaço educacional), é possível tecer questionamentos nos modos como a atividade lúdica é abordada. Serão apresentadas, a seguir, algumas problematizações ao documento, procurando colocar em diálogo o que está proposto nele e o que está proposto na teoria histórico-cultural. Isto será feito considerando três tópicos: a naturalização da infância e da criança, a homogeneização de todas as modalidades de brincadeiras e as relações entre as crianças e os adultos.

1. a naturalização da infância e da criança: nos textos produzidos convivem lado a lado apontamentos sobre a importância de se adotar uma concepção histórica, cultural e social de infância e de criança e a permanência de uma concepção naturalizante e romantizada sobre estas. É possível ler, por exemplo, que os textos estão "partindo do princípio de que o brincar é da natureza de ser criança" (BRASIL, 2006, p.11) e que consideram-na como "ser humano que carrega a leveza da infância" (BRASIL, 2006, p.12); mais adiante, entretanto, afirma-se que "é importante ressaltar que a brincadeira não é algo já dado na vida do ser humano, ou seja, aprende-se a brincar desde cedo, nas relações que os sujeitos estabelecem com os outros e com a cultura (p. 38, ênfases minhas). Além disso, em vários pontos do texto encontram-se enunciações do tipo "A criança é...”, como se uma série de características que podem ser atributos de algumas crianças, fossem atributos inequivocamente compartilhados por todos os sujeitos pequenos, em quaisquer circunstâncias.

Em que pese poder haver modos diferentes de interpretação e de utilização de alguns conceitos da teoria histórico-cultural e divergências em relação a pontos específicos, qualquer tipo de naturalização dos sujeitos e de processos psicológicos é bastante problemática à luz desta abordagem psicológica. Muitas citações poderiam ser trazidas neste ponto, mas creio ser suficiente lembrar que, para Vygotsky, "é a sociedade e não a natureza que deve figurar em primeiro lugar como fator determinante do comportamento do homem. Nisto consiste toda a idéia de desenvolvimento cultural" (VYGOTSKY, 1995a, p.89). Sendo assim, na teoria histórico-cultural, concebe-se que "o processo de desenvolvimento humano é marcado por evoluções, involuções, revoluções. O destino final deste desenvolvimento é marcado dentro dos limites das atividades concretas do grupo 
social em que cada sujeito se insere e a partir do qual se constitui” (VYGOTSKY, 1995, p.89).

Mais especificamente em relação à atividade lúdica, o trabalho de Elkonin (1998) acrescenta contribuições importantes para a compreensão da constituição sócio-cultural e histórica do desenvolvimento do brincar principalmente ao trazer estudos antropológicos que permitem termos clareza de que a atividade de faz-de-conta não é universal entre os diversos grupos culturais, não sendo registrada por antropólogos em várias de suas pesquisas. Ou seja, melhor seria dizer que é possível (mas não inescapável) aprender-se a brincar desde cedo, dependendo das relações que os sujeitos estabelecem com os outros e com a cultura, ou seja, dependendo dos projetos de criança e infância que cada cultura delineia para seus novos membros participantes.

2. a homogeneização de todas as modalidades lúdicas: no documento todas as modalidades de atividades lúdicas são tratadas da mesma forma, sob a rubrica dos termos brincadeiras e brincar. Considero importante lembrar que para os autores da teoria histórico-cultural o jogo de faz-de-conta (ou jogo simbólico, jogo de papéis) é destacado como o tipo de brincadeira mais importante dentre todas. Vale lembrar que se a atividade lúdica é considerada como uma atividade fundamental para o desenvolvimento infantil nas formulações de Vygotsky (1994) e de seus colaboradores (de modo especial A. N. Leontiev e D. Elkonin), é o jogo de faz-de-conta que para este autor constitui-se em zona de desenvolvimento proximal por excelência para a infância.

Ao definir desta maneira esta modalidade de brincadeira, Vygotsky destaca que é através dela que se desenvolvem os processos psicológicos mais importantes de serem garantidos no desenvolvimento das crianças, com especial ênfase para a capacidade de operar no campo simbólico, a independência do campo perceptual imediato, a apropriação de formas culturais de relações e ações sobre o mundo, a linguagem e a imaginação.

Este modo de compreender o faz-de-conta é igualmente compartilhado por Leontiev (1978; 1988), que nomeia esta modalidade de brincadeira como atividade principal da criança. Por atividade principal, o autor entende aquela em torno da qual se organizam as mais poderosas e importantes mudanças psicológicas ao longo da vida de cada sujeito. 
Portanto, em que pese ser importante garantir o ensino e a presença de todas as formas de brincadeiras, cumpre lembrar que nem todas elas trazem o mesmo tipo de contribuições e de impactos para o processo de desenvolvimento infantil.

3. as relações entre crianças e adultos: a tendência para uma visão naturalística da infância - de minha perspectiva - ajuda a explicar o modo como em pontos do texto se analisa as relações entre adultos e crianças. Penso que os excertos seguintes permitem ilustrar estas análises, bem como fazer algumas reflexões importantes: "Podemos aprender com as crianças a crítica, a brincadeira, a virar as coisas do mundo pelo avesso (BRASIL, 2006, p. 19). A criança subverte a ordem estabelecida e estabelece uma relação crítica com a tradição.” (BRASIL, 2006, p.18). “Uma cadeira de cabeça para baixo se torna barco, foguete, navio, trem, caminhão. Aprendemos, assim, com as crianças, que é possível mudar o rumo estabelecido das coisas” (BRASIL, 2006, p.17).

Do ponto de vista histórico-cultural, especialmente quando se toma como referência o trabalho de Elkonin (1998), a constituição da capacidade de criatividade é resultante de um movimento exatamente inverso ao proposto nos trechos acima: são as crianças que num processo lento e gradual e resultante de muitos investimentos de mediação -podem ir aprendendo, especialmente com as pessoas mais velhas e mais experientes de sua cultura, as possibilidades de brincar, criticar e (talvez) virar as coisas pelo avesso. São as formas de mediar o mundo para as crianças que podem ensiná-la que na nossa cultura é legítimo e autorizado que uma cadeira possa, em algumas circunstâncias, tornar-se barco, trem, foguete. Dentre estas pessoas, segundo Elkonin, as(os) professoras(es) devem ocupar lugar de extrema importância, inclusive ensinando seus alunos a brincarem, especialmente considerando os conhecimentos que têm (ou devem ter) sobre os mecanismos psicológicos que estão em jogos nas diferentes modalidades de brincadeiras.

Sendo assim, embora a disponibilização de recursos materiais, o agendamento de tempos e espaços e a observação das brincadeiras desenvolvidas pelas crianças sejam estratégias de muita importância, não são suficientes. E, embora em alguns pontos bastante discretos dos documentos (tanto do RCNEI quanto do guia de Orientações para o Ensino Fundamental de 9 anos) esteja indicada a importância de brincar com as crianças, a observação é a estratégia mais enfatizada nos documentos oficiais. Assim, “a naturalização 
operada na apresentação da brincadeira de papéis sociais como algo inerente ao desenvolvimento infantil acaba por transformar algo construído pela nossa história social como produzido pela natureza” (ARCE, 2006, p. 114) em relação a que às professoras restam poucos e discretos compromissos a assumir.

Pesquisas sobre o lugar da atividade lúdica nos contextos educacionais têm infelizmente - fartamente documentado que é isto que ocorre mais freqüentemente, como veremos a seguir.

\section{A ATIVIDADE LÚDICA NOS CONTEXTOS EDUCACIONAIS:}

Embora exista praticamente unanimidade entre os educadores em considerarem que a atividade lúdica é fundamental para o desenvolvimento infantil, há mais de dez anos pesquisas mostram que o mais comum é identificar-se tendência de tratamento do brincar como uma atividade menos importante nos contextos educacionais. Tem sido enfatizado (e questionado), que nas escolas de Educação Infantil (públicas e particulares) é freqüente ocorrer a priorização de conteúdos e práticas escolarizantes, a instrumentalização da atividade lúdica, o brincar como pausa pedagógica e/ou interdição frontal do brincar (WAJSKOP, 1996; VITAL, 2003; ROCHA, 1995, 2005A; DIAS, 2005; FARIA, 2005, entre outros).

A priorização de conteúdos e práticas escolarizantes no dia-a-dia das crianças revela que há uma tendência de se colocar em primeiro plano a garantia de aprendizagem de determinados conteúdos, em geral os culturalmente mais valorizados (lógico-matemáticos, letramento, etc.). Outras aprendizagens e possibilidades de desenvolvimento, como da capacidade de brincar de faz-de-conta e da imaginação, em geral, ficam deslocados para segundo, terceiro planos. Esta priorização costuma ocorrer ora maneira explícita (na priorização das chamadas atividades dirigidas em que são trabalhados os conceitos acima mencionados), ora aproveitando as situações de brincadeiras para agregar conteúdos escolares; este último tipo de procedimento tem sido nomeado na literatura como didatização (FRANÇA, 1990; WAJSKOP, 1996) ou instrumentalização do brincar (ROCHA, 1995, 2005a). Além disso, a observação do dia-a-dia nas instituições educacionais mostra que não raramente as brincadeiras são frontalmente impedidas (em 


\title{
DOSSIÊ \\ Área Temática: Ensino de Psicologia \\ "Diálogos sobre a Docência em Psicologia"
}

geral porque estão concorrendo com as atividades dirigidas ou porque estão promovendo uma dinâmica mais agitada nas turmas das crianças); muito freqüentemente, observa-se também que as brincadeiras são apenas permitidas, como um momento em que as crianças "gastam energia” e se recuperam para a próxima atividade dirigida. Esta última modulação mostra que as brincadeiras são muitas vezes tratadas como "pausa pedagógica” necessária apenas para a continuidade do trabalho.

Em síntese, as pesquisas evidenciam que nos contextos de educação das crianças pré-escolares, há poucos investimentos em relação ao brincar propriamente dito e fortes tendências de antagonismo entre a valorização do brincar no nível do discurso e os modos como esta atividade é tratada, nas práticas cotidianas. O próprio texto que formula o que se espera do novo Ensino Fundamental reconhece isto ao dizer que:

\begin{abstract}
a significativa produção teórica já acumulada afirmando a importância da brincadeira na constituição dos processos de desenvolvimento e de aprendizagem não foi capaz de modificar as idéias e as práticas que reduzem o brincar a uma atividade à parte, paralela, de menor importância no contexto da formação escolar da criança (BRASIL, 2006, p.36).
\end{abstract}

Se estas são as marcas mais típicas da Educação Infantil, podemos supor que tendam a se acentuar nas instituições de Ensino Fundamental, em cujos objetivos oficialmente formulados não se encontrava, até então, o compromisso de garantir o espaço e as condições necessárias para o brincar.

Esta suposição se confirmou em pesquisa realizada por mim em $2006^{3}$. Com objetivo de compreender os modos como vem sendo construída a vida escolar de crianças de 6 anos em instituições de Ensino Fundamental, foram acompanhadas (através de observação participante) 8 classes turmas de Primeiros Passos de 5 escolas da rede pública municipal de Campinas. Dos resultados, gostaria de destacar alguns pontos.

Em primeiro lugar, as precaríssimas condições materiais para a atividade lúdica que caracterizaram estas escolas em 2006. Ao longo do ano, em apenas uma delas foram

\footnotetext{
${ }^{3}$ Importa informar que neste ano as professoras já dispunham de materiais oficiais orientando - embora com os mesmos problemas identificados no documento para o Ensino Fundamental aqui analisado - para a importância da atividade lúdica na vida escolar das crianças de 6 anos.
} 
instaladas duas gangorras e uma "casinha”. Em relação aos objetos lúdicos, também identificou-se extrema escassez, tanto nas salas de aula quanto em acervos coletivos existentes nestas instituições educacionais. Frente a esta pobreza material, parte das professoras esforçou-se por diminuí-la, com seus próprios recursos, trazendo material de suas casas e produzindo jogos de regras, principalmente com conteúdo pedagógico (bingos de letras, dominós de palavras e números, etc.). Nenhum objeto mais típico para o faz-deconta fez parte do acervo das escolas, durante o período da realização da pesquisa.

O baixo investimento material foi também acompanhado de baixo investimento de participações das professoras nas brincadeiras das crianças. Especialmente em relação ao faz-de-conta, as professoras se mostraram distanciadas: não participaram de nenhum dos (poucos) episódios de brincadeiras deste tipo, ao menos durante as observações realizadas.

Embora não existam pesquisas comparativas sobre os modos de brincar de crianças que participem de contextos educacionais diferenciados em termos das condições (de materiais e de mediações) oferecidas para esta atividade, a teoria histórico-cultural nos dá bons argumentos para supormos que existam prejuízos qualitativos e quantitativos para o desenvolvimento de alguns processos psicológicos (principalmente dos que já foram apontados articulados com os jogos de faz-de-conta), nestas condições educacionais concretas.

Nos dá, também, condições de entender que as perguntas que abriram este texto, embora possam parecer apocalípticas (e, de um certo modo, são mesmo, para serem provocativas de reflexões) podem ter uma resposta afirmativa. $\mathrm{O}$ risco de desaparecimento da atividade lúdica e, de modo especial, dos jogos de faz-de-conta é (dados os modos de funcionamento mais comuns das circunstâncias escolares na contemporaneidade) ao menos do ponto de vista teórico, possível embora - por enquanto - ainda não provável.

Penso não haver riscos em dizer que esta probabilidade está diretamente relacionada às responsabilidades assumidas (ou não) pela Educação Infantil e no prosseguimento da história de implantação do Ensino Fundamental de 9 anos.

Sendo assim, considerando a excelente oportunidade de trabalharmos coletivamente tematizando as relações entre a tarefa de ensinar Psicologia e a Educação Infantil, gostaria de finalizar este texto, sugerindo alguns pontos para início de debate: 
- quais posições pode (deve?) assumir o ensino de Psicologia frente a estas questões?

- se o ensino desta disciplina apontar - insistentemente - para a importância cada vez maior da Educação Infantil em seus compromissos com a atividade lúdica, isto terá repercussões para a vida das crianças neste segmento e também no Ensino Fundamental?

- estas questões devem ocupar lugar prioritário em todo programa de Psicologia que se articule com a Educação Infantil ou existem outras que precisam ser asseguradas com mais ênfase?

\section{REFERÊNCIAS}

ARCE, A. A brincadeira de papéis sociais como produtora de alienação no Referencial Curricular Nacional para a Educação Infantil. In: ARCE, A.; DUARTE, N. (Org.). Brincadeira de papéis sociais na educação infantil: as contribuições de Vigotski, Leontiev e Elkonin. São Paulo: Xamã. 2006.

BORBA, A. M. O Brincar como um modo de ser e estar no mundo. In: BRASIL. Ministério da Educação e Cultura. Ensino fundamental de nove anos: orientações para a inclusão da criança de 6 anos de idade. Mais um ano é fundamental. Brasília: MEC/SEF. 2006.

BRASIL. Ministério da Educação e Cultura. Referencial Curricular Nacional para a Educação Infantil. 3 v. Brasília: MEC/SEF. Vol I: Introdução. 1998a.

Ministério da Educação e Cultura. Referencial Curricular Nacional para a Educação. Infantil. 3 v. Brasília: MEC/SEF. Vol II: Formação Pessoal e Social. 1998b.

Ministério da Educação e Cultura. Referencial Curricular Nacional para a Educação Infantil. 3 v. Brasília: MEC/SEF. VoI Il I: Conhecimento de Mundo. 1998a.

Ministério da Educação e Cultura. Ensino fundamental de nove anos: orientações para a inclusão da criança de 6 anos de idade. Mais um ano é fundamental. Brasília: MEC/SEF. 2006. 
DIAS, L. S. Infâncias nas brincadeiras: um estudo em creche pública e em creche privada. 2005. Dissertação (Mestrado em Educação) - Faculdade de Educação. Universidade Estadual de Campinas, Campinas, 2005.

ELKONIN, D. B. Psicologia do jogo. São Paulo: Martins Fontes. 1998.

FARIA, A. L. G.; PALHARES, M. S. et al. Educação infantil pós-LDB: rumos e desafios. Campinas: Autores Associados. 1999.

FARIA, A.L. G. Políticas de regulação, pesquisa e pedagogia na educação infantil, primeira etapa da educação básica. Educ. Soc, , v.26, n.92, p.1013-1038, out. 2005.

FRANÇA, G. W. Tia, me deixa brincar: o espaço do jogo na educação pré-escolar. 1990 Dissertação (Mestrado em Educação) - Faculdade de Educação. Pontifícia Universidade Católica de Campinas, Campinas, 1990.

LEONTIEV, A. N. O desenvolvimento do psiquismo. Lisboa: Horizonte Universitário. 1978.

LEONTIEV, A. N. Os princípios psicológicos da brincadeira pré-escolar. In: VIGOTSKII, L. S.; LURIA, A. R.; LEONTIEV, A. N. Linguagem, Desenvolvimento e Aprendizagem. São Paulo: Ícone. 1988.

ROCHA, M. S. P. M.L. A constituição social do brincar: modos de abordagem do real e do imaginário no trabalho pedagógico. 1995. Dissertação (Mestrado em Educação) Faculdade de Educação. Universidade Estadual de Campinas, Campinas, 1995.

ROCHA, M. S. P. M. L. Não brinco mais: a (des)construção do brincar na educação infantil. Ijuí: Unijuí. 2005a.

VIGOTSKI, L. S. Teoria e método em psicologia. São Paulo: Martins Fontes. 1996.

. A formaação social da mente. São Paulo: Martins Fontes. 1994.

Obras escogidas. Madrid: Visor. 1995. v.3.

. Obras escogidas. Madri: Visor Distribuciones. 1995a. v.4.

VITAL, M. R. A priorização dos conteúdos escolares em detrimento das atividades lúdicas na educação infantil. 2003. Dissertação (Mestrado). Universidade Presbiteriana Mackenzie. 2003. 


\section{DOSSIÊ \\ Área Temática: Ensino de Psicologia \\ "Diálogos sobre a Docência em Psicologia"}

WAJSKOP, G. Concepções de brincar entre profissionais de educação infantil: implicações para a prática institucional. 1996. Tese (Doutorado em Educação) - Faculdade de Educação. Universidade de São Paulo. 1996.

MARIA SILVIA PINTO DE MOURA LIBRANDI DA ROCHA

Graduada em Psicologia pela Puc-Campinas e professora desta Universidade, nas faculdades de Psicologia e Pedagogia. Obteve títulos de mestre e doutora na Faculdade de Educação da Unicamp, na área de

Psicologia da Educação. É autora do livro "Não brinco mais: a (des)construção do brincar no cotidiano educacional", publicado pela Editora Unijuí. Atualmente, desenvolve a pesquisa "A criança de 6 anos e

o Ensino Fundamental", vinculada a seu projeto de carreira docente.

E-mail: silrocha@uol.com.br

Recebido em: 25/05/2007

Publicado em: 14/06/2007 